\title{
Annotation
}

\section{Heart valve replacement}

In the past 25 years open intracardiac surgery has made replacement of the heart valves possible, and in this same period a variety of valve substitutes have been developed. Progressive improvements in the quality and reliability of these substitutes has meant that valve replacement in adults can be performed quickly with relatively satisfactory short, medium, and indeed long term results. The situation in infants and young children, however, is far from satisfactory.

\section{Conditions in which heart valve replacement is useful}

In the United Kingdom most children requiring valve replacement do so because of congenital heart lesions, while in developing countries rheumatic carditis remains a common cause of valvar diseases. The congenital abnormalities may be either confined to the valve itself, as is the case in isolated aortic stenosis, mitral valve stenosis, and Ebstein disease of the tricuspid valve, or may affect other cardiac structures resulting in complex haemodynamic dysfunctions like those found in transpositions, pulmonary atresia, truncus arteriosus, tricuspid atresia, and univentricular hearts.

In the former group, the abnormal valve needs replacement when conservative procedures seem either impossible or fail to achieve a satisfactory result. In the latter group, the valve substitute is part of an extracardiac conduit used to connect the right ventricle or the right atrium to the pulmonary artery.

\section{Types of heart valve substitute}

There are fundamentally three types of heart valve substitutes available to the surgeon at present.

Mechanical valves. A variety of technical modifications in the design of prosthetic heart valves has occurred, but in general these are either 'ball in cage' type valves or one or other of a variety of disc valves. The latter have the advantage of being 'low profile', and recent models wholly made from pyrolitic carbon give maximal internal effective valve orifice for a given size external valve sewing ring, offering an improved hydraulic design with, at least theoretically, a diminished likelihood of thromboembolic complications.

Xenografts. These are framemounted, bioprosthetic valves. The animal tissue may be a heart valve, for example the pig aortic valve or bovine pericardium.

Homografts. The aortic root is collected from human cadaver shortly after death and preserved in a solution of antibiotics and nutritional medium for later use.

\section{Choice of valve substitute}

Unfortunately, a satisfactory valve substitute for children does not yet exist. This is why surgeons dealing with children maximise efforts to repair insufficient valves, at times accepting a less than optimal result to avoid valve replacement. In choosing the most suitable valve substitute many factors are to be taken into consideration.

Location within the heart. Aortic homografts are at present the best choice for aortic valve replacement. ${ }^{1}$ Xenografts show early degeneration and calcification in the aortic and mitral position, less so in the tricuspid position and inside conduits on the systemic venous side of the heart. ${ }^{2-6}$ Mechanical valves, especially the low profile disc types, may be used in the mitral and tricuspid position. ${ }^{7}$

Availability. Homografts are not always readily available in all sizes and surgery needs to be planned in advance.

Duration. If valve replacement takes place at a very young age all types of valve substitutes need later replacement when the heart increases in size. Mechanical valves theoretically last for a lifetime, homografts may reasonably be expected to last for 10 to 15 years, and xenografts only a few years at best.

Anticoagulation. Children are accident prone, and treatment with anticoagulants is therefore undesirable. Homograft and xenograft valve substitutes do 
not require anticoagulation, while, in our view, mechanical valves always do.

Endocarditis. Endocarditis represents a definite risk with any valve substitute, and antibiotic prophylaxis is essential for intercurrent infections and dental treatment.

Noise. Tissue valves are silent, but mechanical prosthesis produce a click which may at times be very distressing.

There are, therefore, major advantages and disadvantages of the different valve substitutes. Our present attitude is to avoid valve replacement if at all possible. Where this is not possible, homograft valve substitutes are selected, if a suitable valve size is available, in the aortic and right heart positions. A homograft aortic valve with an attached length of aortic wall is the valve substitute of choice when a valve mechanism plus conduit is needed to restore continuity between the right atrium or right ventricle and pulmonary artery, or occasionally between the left ventricle and pulmonary artery in certain complex types of transposition. In the tricuspid position, the rate of degeneration of a xenograft seems less rapid than in the mitral and aortic position. In this location, either a bioprosthetic or mechanical valve may be used. Our own preference at present is to use the bileaflet, pyrolitic carbon, low profile St Jude prosthesis in the tricuspid location and to prescribe anticoagulants and antiplatelet drugs after surgery. We also use the St Jude valve in the mitral position with the same policy after surgery. In the aortic position the St Jude valve is our second choice as a valve substitute when a suitable size homograft is not available.
In conclusion, valve replacement in infants and young children is now a feasible, technically reliable method of handling isolated or complicated valve insufficiency, but the results of using the variety of valve substitutes available remain unsatisfactory. Our current attitude is to avoid whole valve substitutes if at all possible, especially with the aortic and mitral valves, and to make strenuous efforts to repair the valve-even to the extent of accepting a degree of residual malfunction of the native valve.

\section{References}

1 Penta A, Qureshi S, Radley-Smith R, Yacoub MH. Patient status 10 or more years after 'fresh' homograft replacement of the aortic valve. Circulation 1984;70:1182-6.

2 Antunes MJ. Bioprosthetic valve replacement in children-long term follow up of 135 isolated mitral valve implantations. Eur Heart J 1984;5:913-8.

${ }^{3}$ Miller DC, Stinson EB, Oyer PE, et al. The durability of porcine xenograft valves and conduits in children. Circulation 1982;66:1172-85.

4 Sanders SP, Levy RJ, Freed MD, Norwood WI, Castaneda AR. Use of Hancock porcine xenografts in children and adolescents. Am J Cardiol 1980;46:429-38.

5 Walker WE, Duncan JM, Frazier OH Jr, et al. Early experience with the ionescu-shiley pericardial xenograft valve. Accelerated calification in children. J Thorac Cardiovasc Surg 1983;86 570-5.

6 Williams DB, Danielson GK, McGoon DC, Puga Fs Mair DD, Edwards WD. Porcine heterograft valve replacemen in children. J Thorac Cardiovasc Surg 1982;84:446-50.

7 Schaff HV, Danielson GK, DiDonato RM, Puga FJ, Mair DD', McGoon DC. Late results after Starr-Edwards valve replacement in children. J Thorac Cardiovasc Surg 1984;88:583-9.

P B Deverall, G Campalani, AND D R ANDERSON Guy's Hospital, St Thomas Street, London SE1 9RT 